\title{
Neuromuscular blockade at the larynx, the diaphragm and the corrugator supercilii muscle: a review
}

\author{
[Blocage neuromusculaire du larynx, du diaphragme et du muscle sourcilier : une revue]
}

Thomas M. Hemmerling MD DEAA, François Donati MD PhD FRCPC

Purpose: To review recent findings concerning neuromuscular blockade and monitoring at the larynx, the diaphragm, and the corrugator supercilii muscle.

Source: This narrative review is based on recent publications.

Principal findings: Neuromuscular blockade at the larynx and the diaphragm is less intense than at the adductor pollicis muscle; the onset and offset of neuromuscular blockade is more rapid. The corrugator supercilii muscle reflects better the time course of neuromuscular blockade of the larynx than the adductor pollicis muscle, is better suited to monitor the onset of neuromuscular blockade for intubation, and should give a better reflection of the time course and degree of neuromuscular blockade of the larynx or the diaphragm. Recovery of neuromuscular function at the end of any procedure is best reflected at the adductor pollicis muscle where neuromuscular transmission is last restored. Clinical monitoring of the larynx or the diaphragm is still limited by the absence of a simple method. Acceleromyography of the corrugator supercilii muscle is prone to artifacts that do not occur during monitoring of the adductor pollicis muscle. Phonomyography, a new method of monitoring that is currently being tested, is based on the phenomenon that muscle contraction creates low-frequency sound waves, which can be detected using special microphones to quantify neuromuscular blockade. This method seems promising because it can be easily used on all muscles of interest.

Conclusion: Research during the last 15 years has greatly enhanced our knowledge about how muscles react differently to muscle relaxants and has enabled us to achieve better surgical conditions with safer use of muscle relaxants. Interesting technologies have been developed to reliably monitor neuromuscular blockade at the larynx and the diaphragm, but are currently restricted to research settings. Our increased understanding should help us in ongoing efforts to develop the "ideal" muscle relaxant and the "ideal" method of neuromuscular monitoring.
Objectif : Passer en revue les derniers résultats de recherches sur le blocage neuromusculaire et le monitorage du larynx, du diaphragme et du muscle sourcilier.

Source : Cette revue traditionnelle porte sur des publications récentes.

Constatations principales : Le blocage neuromusculaire du larynx et du diaphragme est moins intense que celui de l'adducteur du pouce ; le délai d'installation et le renversement du bloc sont plus rapides. Le muscle sourcilier montre mieux l'évolution du blocage neuromusculaire du larynx que le muscle adducteur du pouce, convient mieux au monitorage du début du blocage neuromusculaire pour l'intubation et devrait donner une meilleure idée de l'évolution et du degré de blocage neuromusculaire du larynx ou du diaphragme. La récupération de la fonction neuromusculaire postopératoire est mieux démontrée au muscle adducteur du pouce où la transmission neuromusculaire est restaurée en dernier. Le monitorage clinique du larynx ou du diaphragme demeure limité par l'absence d'une méthode simple. L'accéléromyographie du muscle sourcilier expose à des artéfacts qui ne surviennent pas pendant le monitorage de l'adducteur du pouce. La phonomyographie, une nouvelle méthode de monitorage présentement expérimentée, se fonde sur le fait que la contraction du muscle crée des ondes sonores de basses fréquences qui peuvent être détectées avec l'usage de microphones spéciaux pour quantifier le blocage neuromusculaire. Cette méthode semble prometteuse, car elle est facilement utilisable pour tous les muscles qui nous intéressent.

Conclusion : La recherche des 15 dernières années a beaucoup apporté à notre compréhension sur la réaction différente des muscles aux myorelaxants et nous a permis d'offrir de meilleures conditions chirurgicales en utilisant les myorelaxants de façon plus sécuritaire. D'intéressantes technologies ont été mises au point pour le monitorage fiable du blocage neuromusculaire du larynx et du diaphragme, mais elles sont actuellement réservées à la recherche. Les nouvelles découvertes vont contribuer aux efforts permanents visant à élaborer le myorelaxant "idéal" et la méthode de monitorage "idéale".

From the Department of Anesthesiology, Hôtel-Dieu, Centre Hospitalier de l'Université de Montréal, Université de Montréal, Montréal, Québec, Canada.

Address correspondence to: Dr. Thomas M. Hemmerling, Centre Hospitalier de l'Université de Montréal (CHUM), Hôtel-Dieu,

Département d'anesthésie, 3840, rue Saint-Urbain, Montréal, Québec H2W 1T8, Canada. Phone: 514-890-8000, ext. 14570;

Fax: 514-412-7222; E-mail: thomashemmerling@hotmail.com

Accepted for publication December 4, 2002.

Revision accepted February 28, 2003. 
I $\mathrm{N}$ the ideal world, we would have a non-depolarizing neuromuscular blocking agent (NMBA) with ultra-short onset and offset of action, without side-effects, metabolized by reactions independent of any organ function, and leaving no active metabolite. We would be able to easily and reliably monitor neuromuscular function for all physiologically important muscles in a non-invasive fashion. Finally, we would have established reliable data for any given muscle relaxant with regards to onset, offset and peak effect for different muscles. In reality, the ideal NMBA and the ideal neuromuscular monitor are still to be found; however, recent findings have greatly enhanced our knowledge of neuromuscular blockade with current NMBAs and of neuromuscular monitoring at the larynx, the diaphragm and the corrugator supercilii muscle.

Most clinicians use nerve stimulators regularly to monitor neuromuscular function, but the response is still usually evaluated by tactile and visual examination; therefore, the control of neuromuscular blockade is not very accurate. As monitoring site, most anesthesiologists use the adductor pollicis muscle, whose neuromuscular transmission returns later than that of the diaphragm and laryngeal muscles. Recovery of the upper airway muscles and the adductor pollicis muscle occur at approximately the same time, so the safest conditions for extubation are achieved only when neuromuscular transmission has returned completely at the latter.

For onset of action, monitoring at the eyebrow muscles is more valid and correlates better with onset and degree of neuromuscular blockade at the larynx. For most types of surgery, determination of muscle relaxation at the surgical site is impossible. In clinical practice, we must be aware of the difference between the monitored muscle and those at the surgical site. Tactile and visual methods provide subjective estimates of the degree of muscle relaxation. Mechanomyography, electromyography, acceleromyography and most recently, acoustic myography or phonomyography are more objective methods of monitoring. For clinical use, mechanomyography (force measurement) remains the "gold standard", but these devices are cumbersome and have been restricted to the adductor pollicis muscle. Electromyographic devices are expensive, unreliable, and do not correlate with the measurement of force. For acceleromyographic devices, the train-of-four (TOF) Watch ${ }^{\circledR}$ (Organon Technika, Boxlet, The Netherlands) is currently the most commonly used. There are conflicting data regarding its agreement with mechanomyography. Although it has been validated for the adductor pollicis muscle, it cannot be used for the larynx or the diaphragm. Phonomyography is still in an early developmental stage, but seems promising. Presently, no device can be used to routinely monitor the diaphragm or the larynx during surgery. Limiting factors include the problem of stimulation of the concomitant nerve (phrenic nerve) and the absence of non-invasive and easy-to-use methods of monitoring (larynx).

Numerous studies have demonstrated the differences between neuromuscular blockade at more central muscles, such as those of the larynx and the diaphragm, and peripheral muscles. Although we now know more about the time course and the degree of neuromuscular blockade at different muscles, the absence of data on each method of neuromuscular monitoring for all these muscles remains a major problem. Given that methods of neuromuscular monitoring cannot be used interchangeably, the influence of using different methods to monitor different muscles is problematic and has not been properly evaluated.

The objective of this article is to review data produced in the last $\mathbf{1 5}$ years about neuromuscular blockade at the laryngeal adductors and the diaphragm. Comparisons with muscles of the hand and around the eye will be highlighted. The inclusion of video-sequences is an attempt to bring neuromuscular research closer to these anesthesiologists by demonstrating research tools which have been developed and used during the last decade and are not part of daily routine (video sequences are included with the online version of this review at www.cjajca.org). Finally, guidelines on how to use and monitor muscle relaxants according to the present research knowledge will be presented.

\section{Larynx}

Anatomy and physiology

The important physiologic functions of the larynx include the protection of the lower airway, respiration, and phonation. In anesthesia, complete relaxation of the vocal cords is needed for excellent intubation conditions, and complete recovery of neuromuscular transmission of all laryngeal muscles facilitates airway protection at extubation. The opening and closing of the larynx are controlled by extrinsic and intrinsic muscles acting on the passive mass and elastic forces of the tongue, pharynx, larynx and trachea. Figure 1 shows the anatomy of the larynx. ${ }^{1}$

The glottis is defined as the area containing the vocal cords and the arytenoids. The vocal cords are formed by the superior free edge of the cricothyroid ligaments. Three intrinsic muscles close the glottis. The aryepiglottic muscle is attached to the lateral border of the epiglottic cartilage anteriorly and to the ipsilateral arytenoid cartilage posteriorly. The thy- 


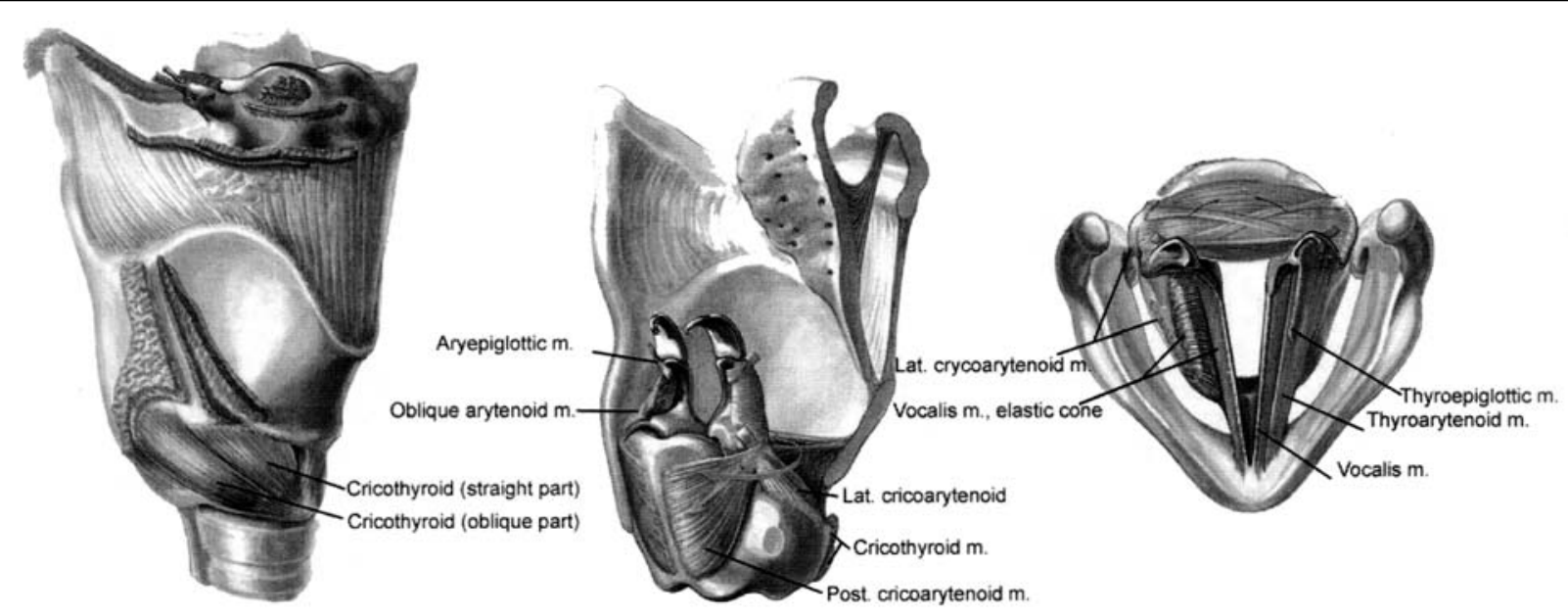

FIGURE 1 The anatomy of the larynx, from left to right: anterolateral view; posterior view; transverse axial view onto the vocalis muscles from above (adapted from Pernkopf Anatomy: Atlas of Topographic and Applied Human Anatomy). ${ }^{1}$

roepiglottic muscle is attached laterally to the lamina of the thyroid cartilage and medially to the epiglottis. These two muscles pull the epiglottis down over the laryngeal inlet. The oblique arytenoid muscle joins the two arytenoid cartilages and aids in closing the laryngeal inlet.

Five muscles act on the true vocal folds, which extend from the vocal process of the arytenoid cartilage to the deeper parts of the laryngeal prominence. The cricothyroid muscle extends from the arch of the cricoid cartilage to the lower border of the thyroid lamina and inferior horn of the thyroid cartilage. Its contraction tilts the thyroid cartilage and lengthens the vocal folds. The cricothyroid muscle is the only intrinsic laryngeal muscle that is innervated by the external laryngeal nerve instead of by the recurrent laryngeal nerve. The lateral cricoarytenoid muscle extends from the upper border of the arch of the cricoid cartilage to the lateral muscular process of the arytenoid cartilage, and approximates the arytenoid cartilages and closes the vocal folds. The posterior cricoarytenoid muscle is attached to the lamina of the cricoid cartilage and the lateral muscular process of the arytenoid cartilage, and causes rotation and gliding of the arytenoids on the upper border of the cricoid lamina. The posterior cricoarytenoid is the only abductor of the vocal folds.

The thyroarytenoid muscle extends from the deep aspect of the laryngeal prominence to the vocal process of the arytenoids cartilage and opposes the shortening of the vocal folds by the cricothyroid mus- cle. Some fibres of this muscle (known as the vocalis muscle) extend from the arytenoid cartilage to the cricovocal membrane (part of the conus elasticus). During phonation, contraction of conus elasticus elevates part of the cricovocal membrane. The thyrohyoid and sternohyoid muscles are the principal extrinsic laryngeal muscles. They secure the larynx in position and move it vertically.

Morphologically, the intrinsic muscles of the larynx differ from most other muscles of the body because of the multiple endplates for each fibre. Some of these muscles consist of up to $70 \%$ muscle fibres with multiple motor end plates. This percentage differs between muscles, ranging from $50 \%$ for the cricothyroid muscle to $5 \%$ for the posterior cricoarytenoid muscle. ${ }^{2,3}$ Regardless of the number of endplates, they are "twitch" fibres, that propagate an action potential and contract in an all-or-none fashion. In contrast, "non-twitch" fibres (for example, in the extraocular muscles) do not propagate an action potential and respond in a graded fashion. Intrinsic muscles of the larynx have a large proportion of fast type II muscle fibres, which differ from slow type I fibres regarding a slightly different myofibrillar adenosine triphosphate (ADP), with variations between muscles. In monkeys, contraction times are short for the thyroarytenoid and lateral cricoarytenoid muscles (14 and $19 \mathrm{msec}$ ) with high ATPase activity and slower for the cricothyroid and posterior cricoarytenoid muscles (36 and 44 msec, respectively). ${ }^{4}$ 


\section{Innervation}

The motor units of the intrinsic muscles, except the cricothyroid muscle, are innervated by the recurrent laryngeal nerve, which originates in the nucleus ambiguous in the medulla oblongata and supply the ipsilateral muscles. The right recurrent laryngeal nerve lies in front of the right subclavian artery and hooks below it to ascend in the right tracheo-esophageal groove. The left recurrent laryngeal nerve passes by the side of the aortic arch, loops below it, and ascends behind the aortic arch to the left tracheo-esophageal groove.

Clinical aspects of neuromuscular blockade at the larynx Complete vocal cord paralysis and laryngeal relaxation facilitates tracheal intubation and reduces the risk of damage to the vocal cords during insertion of the endotracheal tube. Some recent studies have questioned the need for neuromuscular blocking drugs for tracheal intubation, ${ }^{5,6}$ but deep anesthesia was needed. Neuromuscular blockade before intubation reduced significantly the dose of propofol required in one study. ${ }^{7,8}$ At this point, uncertainty remains regarding whether deep anesthesia merely reduces the patient's reaction to intubation or relaxes laryngeal muscles. A recent study showed a potential "relaxant" effect of propofol in vitro."

The need for laryngeal relaxation as in laryngeal surgery, or the need for laryngeal mobility as in thyroid surgery depends on the depth of anesthesia. A large series of thyroid surgical procedures without neuromuscular blockade - to enable neurophysiological monitoring of recurrent nerve function - demonstrated that the appropriate choice of anesthetic agents and profound depth of anesthesia reduces the need for neuromuscular blockade. ${ }^{10}$

The economic pressure to reduce the amount of NMBAs used during surgery, and the desire to better titrate NMBAs, underline the need for a more detailed understanding of the differences of the neuromuscular blockade at the larynx in comparison to the adductor pollicis muscle.

\section{Stimulation of the recurrent laryngeal nerve}

In research, there are two possible sites for percutaneous stimulation of the recurrent laryngeal nerve. This nerve can be stimulated either using two superficial electrodes, glued between the jugular notch and the cricoid cartilage (Video 1) or, with the use of bipolar stimulation probe just medial to the sternocleidomastoid muscle in the tracheo-esophageal groove (Video 2). In comparison to stimulation of the phrenic nerve, concomitant stimulation of the axillary plexus is rare and concomitant stimulation of the vagus nerve has not been reported as a complication.

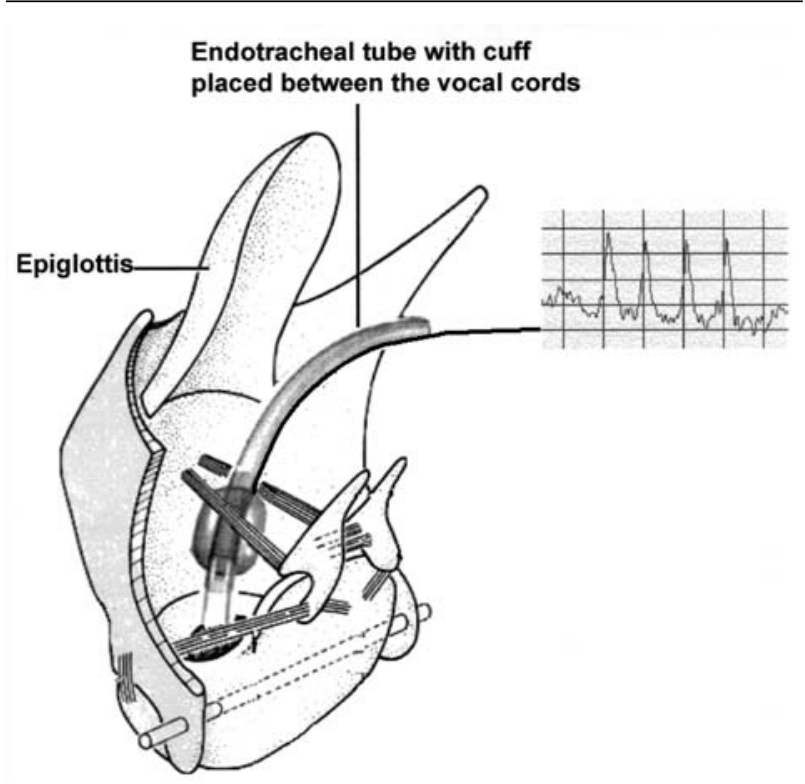

FIGURE 2 Monitoring the force of laryngeal adduction. The cuff of an endotracheal tube is placed between the vocal cords and the pressure changes inside the cuff are recorded. Force of adduction corresponds with the amplitude of pressure changes. The inset picture shows a typical recording of pressure changes after train-of-four stimulation.

\section{Monitoring neuromuscular blockade at the adducting laryngeal muscles}

The response of the laryngeal adductor muscles is measured by placing the cuff of the endotracheal tube between the vocal cords and measuring the pressure changes within the cuff (Figure 2). ${ }^{11}$ Maintenance of the resting pressure within the cuff is important. ${ }^{12}$

Electromyography of the larynx can be accomplished by using either a specialized endotracheal tube with incorporated wire electrodes ${ }^{13}$ or a superficial electrode attached circularly around the tube and placed between the vocal cords. ${ }^{14}$ This superficial electrode gives the same results as im electrodes inserted into the intrinsic laryngeal muscles, predominantly the lateral cricoarytenoid muscles. ${ }^{15}$ Electromyography records the evoked compound action potential of the adductors and the abductor of the cords. A comparison of laryngeal electromyography and the cuff pressure technique has not been reported.

\section{Differences between neuromuscular blockade at the lar- ynx and the adductor pollicis muscle \\ Most studies confirm that onset of neuromuscular blockade is faster and recovery is earlier at the larynx}




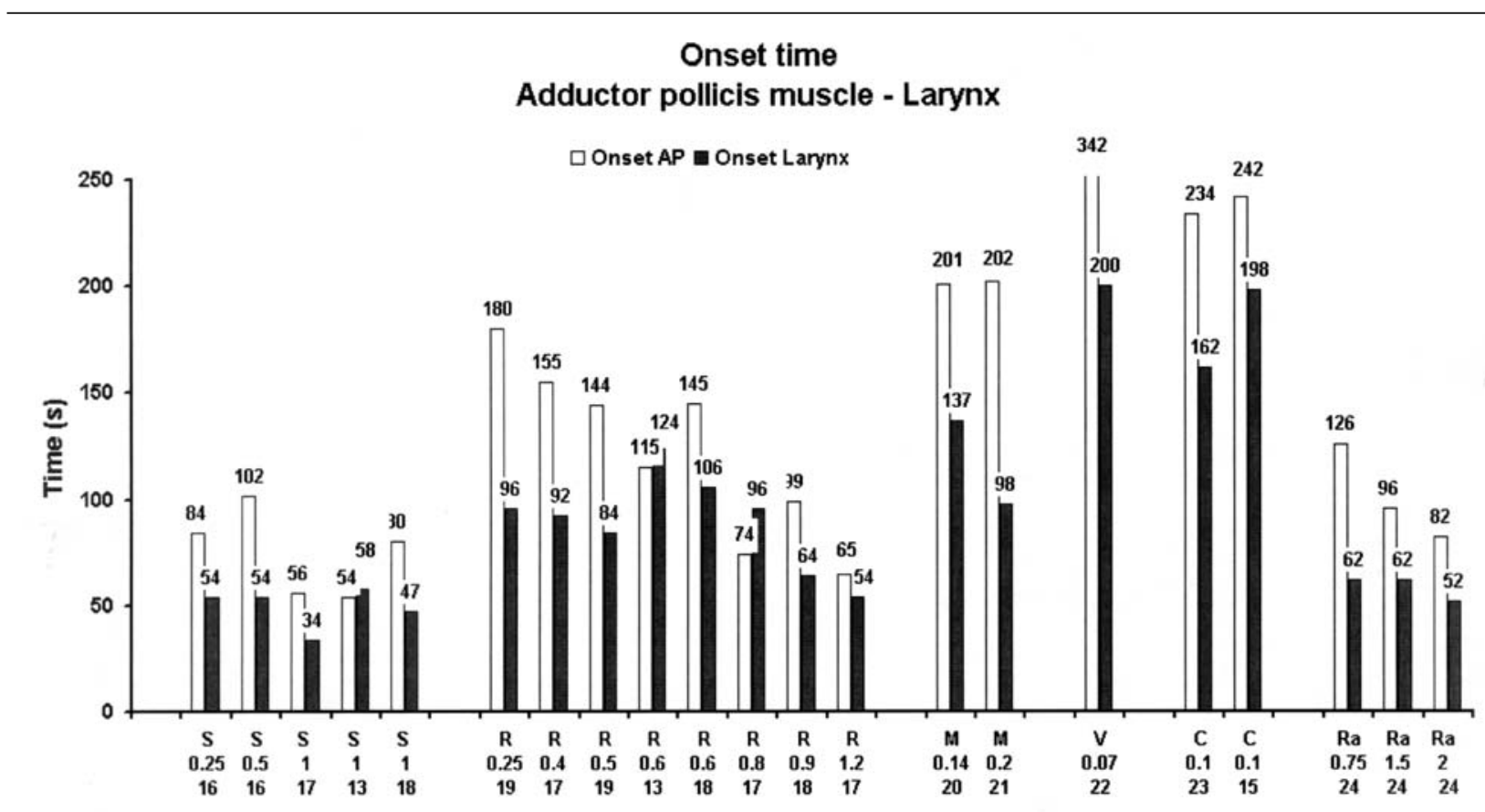

T $25 \%$

Adductor pollicis muscle - Larynx

$\square$ T25 AP $\square$ T25 Larynx

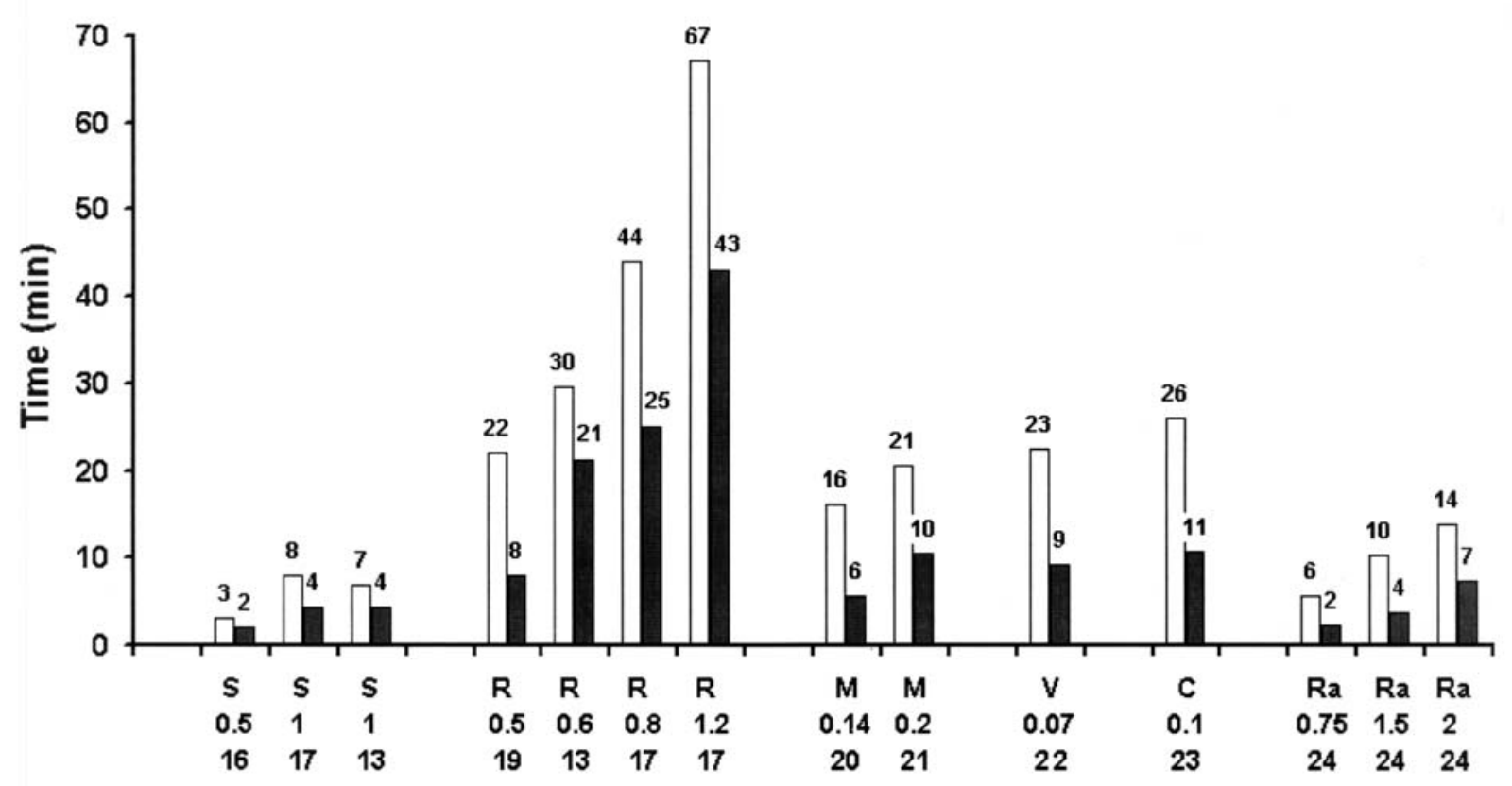

FIGURE 3 Bar graphs summarizing the results of studies that measured (a) onset and (b) clinical duration of neuromuscular blockade after injection of various neuromuscular blocking agents simultaneously at the larynx (white columns) and the adductor pollicis muscle (black columns). $\mathrm{C}=$ cisatracurium; $\mathrm{M}=$ mivacurium; $\mathrm{R}=$ rocuronium; $\mathrm{Ra}=$ rapacuronium; $\mathrm{S}=$ succinylcholine; $\mathrm{V}=$ vecuronium. The second and third lines on the $\mathrm{X}$-axis indicate the doses $\left(\mathrm{mg} \cdot \mathrm{kg}^{-1}\right)$ and the study reference number respectively. 
when compared to the adductor pollicis (Figure 3a, b). When subparalyzing doses of NMBAs are used, the peak effect at the larynx is less than at the adductor pollicis muscle. To obtain nearly $100 \%$ blockade at the larynx, doses greater than twice the dose necessary to produce $95 \%$ blockade at the adductor pollicis muscle $\left(\mathrm{ED}_{95}\right)$ must be given. The relative resistance of laryngeal muscles to NMBAs may be caused by a greater acetylcholine receptor density in fast twitch muscle ${ }^{25}$ or by the larger number of receptors relative to fibre size. ${ }^{26}$ Whereas the faster onset of NMBAs at the larynx is most probably due to a greater blood flow to centrally located muscles ${ }^{27}$ the reason for the faster recovery is largely the result of the morphological differences between the larynx and the adductor pollicis muscle.

\section{Differences between adducting and abducting laryn- geal muscles}

Only two animal studies and one human study have investigated neuromuscular blockade at different laryngeal muscles. In cats, ${ }^{28}$ onset and recovery after vecuronium and rocuronium were the same for the posterior cricoarytenoid muscles and the tibialis muscle. The lateral cricoarytenoid muscle and the thyroarytenoid muscle had a slower onset and a more prolonged recovery. If the anterior tibial muscle is regarded as equivalent to the adductor pollicis muscle, this is clearly different from all human studies. Iwasaki and coworkers ${ }^{29}$ also found in dogs that the onset and peak effect of neuromuscular blockade was similar between the posterior cricoarytenoid (abductor) muscle and the anterior tibial muscle. The cricothyroid was more sensitive. In humans, the onset was fastest for the adductor pollicis muscle, followed by the cricothyroid muscle and the posterior cricoarytenoid muscle with less intense block in the laryngeal muscles. ${ }^{30}$ Recovery was not measured in that study. Comparisons of recovery were not made with the adductor pollicis muscle of the larynx. Although limited, the evidence from animal studies indicates that there might be differences between the intrinsic laryngeal muscles in their sensitivity to NMBAs. More detailed and controlled studies are needed to investigate the possible differences between neuromuscular blockade at the adducting and abducting laryngeal muscles.

\section{What can be deduced from comparative studies of lar- ynx and adductor pollicis?}

Peak effect is generally lower at the larynx than at the adductor pollicis muscle with lower injected doses resulting in greater differences. Doses lower than an $\mathrm{ED}_{95}$ can create peak effects of only $50 \%$ or less at the larynx. However, doses higher than the $\mathrm{ED}_{95}$ for suc- cinylcholine, rocuronium, mivacurium, cisatracurium, and rapacuronium are sufficient to reach a peak effect of at least $85 \%$ at the larynx. Calculations based on the mean onset times for the adductor pollicis and of the adducting laryngeal muscles provided in all studies where doses of $2 \times \mathrm{ED}_{95}$ were used (Figure $3 \mathrm{a}, \mathrm{b}$ ) generally show that the peak effect at the larynx is reached after $75 \%(50-130 \%)$ of the time needed to reach the higher peak effect at the adductor pollicis. The clinical duration of the neuromuscular blockade (T 25\%) at the larynx is only half $(40-70 \%)$ of the clinical duration at the adductor pollicis muscle. In summary, onset at the larynx is faster, peak effect is less, and recovery occurs sooner than at the adductor pollicis muscle.

\section{Diaphragm}

Anatomy and physiologic function

The diaphragm constitutes the great muscular septum between the thoracic and abdominal cavity. It is a peripheral muscle with a central trefoiled-shaped tendon of strong interlacing bundles blending above with the fibrous pericardium. The apex of the dome of the diaphragm reaches the level of the fifth rib in the midclavicular line, with the right hemidiaphragm being higher than the left.

The movement of the diaphragm accounts for 60 to $75 \%$ of the total tidal volume of respiration. In addition, the diaphragm plays an important role in the mechanism of the cardiac sphincter. The cardiac sphincter allows food and liquid passage into the stomach, yet prevents free regurgitation. The diaphragmatic sling maintains the normal position of the cardia and has a pinchcock action on the lower esophagus.

The phrenic nerve originates from the cervical plexus (C3-5), provides the motor innervation for the diaphragm, and transmits proprioceptive fibres from the centre of the diaphragm. The three roots of the nerve join at the lateral border of scalenus anterior and then run caudally and medially on the surface of the muscle. The nerve is overlapped by the internal jugular vein and sternocleidomastoid muscle and is crossed by the inferior belly of the omohyoid muscle and by the transverse cervical and transverse scapular vessels. It enters the thorax, runs through the mediastinum, and inserts with its terminal fibres on the abdominal side of the diaphragm.

\section{Stimulation of the phrenic nerve}

The cervical anatomy of the phrenic nerve explains the best sites and techniques of stimulation (Figure 4). Whereas the recurrent laryngeal nerve can be stimulated easily via superficial electrodes due to its more superficial cervical pathway, this is not possible for the phrenic 


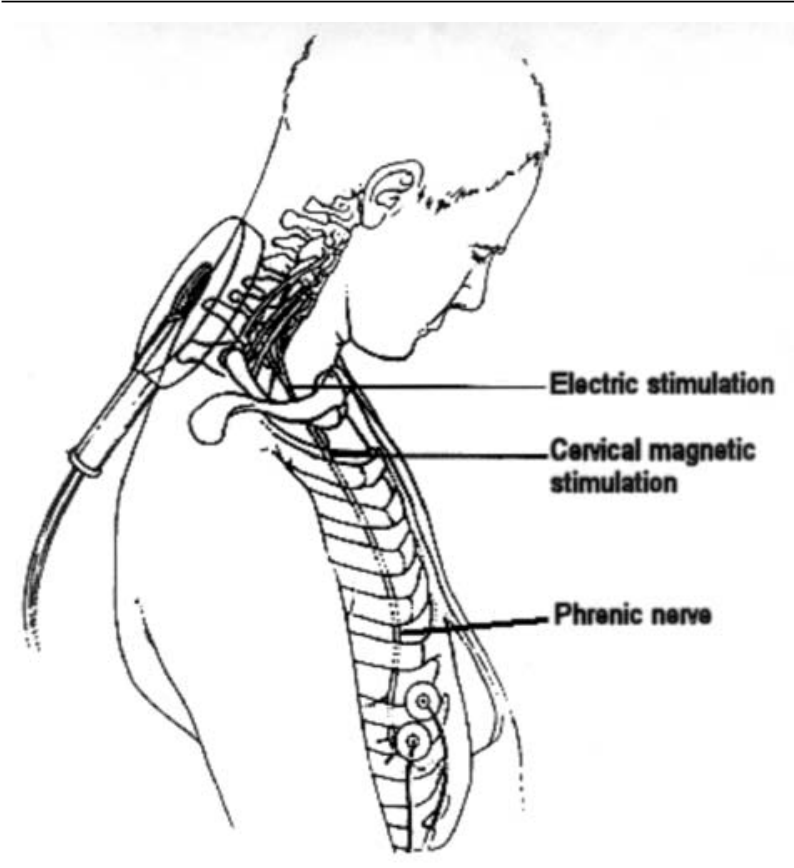

FIGURE 4 Path of the phrenic nerve from its cervical origin to its insertion into the diaphragm. Areas of focused energy for electric stimulation and cervical magnetic stimulation are shown.

nerve. Earlier studies have used needle electrodes to stimulate the nerve percutaneously at the border of the anterior scalenus muscle. Although this technique allows stable stimulation with low currents, its invasiveness risks direct nerve damage or bleeding. Most studies have used a hand-held stimulator that has allowed investigators to direct the current more internally on the two main sites for stimulation: directly above the clavicle, in the midclavicular line directed caudally or, more recently, posterior to the sternocleidomastoid muscle, where the nerve roots exit the cervical plexus (Video 3). Both sites bear the risk of concomitant stimulation of the brachial plexus, partially due to the high stimulation currents of up to 70 to $80 \mathrm{~mA}$, which may cause artifacts in recording the diaphragmatic response and, mostly due to shoulder movements, disturb the proper stimulation of the phrenic nerve itself. In comparison to the stimulation of the recurrent laryngeal nerve, stimulation of the phrenic nerve is more cumbersome, needs more practice, and cannot easily be introduced into clinical practice.

A possible alternative to electrical stimulation of the cervical portion of the phrenic nerve is the magnetic stimulation of the cervical or thoracic part of the nerve. ${ }^{31-36}$ Its theoretical advantage is the almost pain- less stimulation and the ease of application of the electrodes, which do not touch the patient's skin. It has been widely used in conscious volunteers and patients for pneumological and physiological diagnosis and research. It has been used in critical care to examine diaphragmatic fatigue. It produces results similar to electrical stimulation; ${ }^{37-39}$ however, concomitant stimulation of the brachial plexus remains a problem, ${ }^{40}$ high costs as well as technical limitations of the stimulators, such as difficulty in stimulating at the classical modes like TOF, have prevented any use in neuromuscular anesthetic research. Transcutaneous superficial stimulation of the phrenic nerve cannot be used in daily neuromuscular monitoring.

\section{Monitoring neuromuscular blockade at the diaphragm} The most common method of measurement has been electromyography using percutaneous needles or superficial skin electrodes. ${ }^{13,41-43}$ The conventional site for electromyographic recording has been the seventh or eighth intercostal space (Figure 5a), between the anterior axillary and the mid-clavicular line. ${ }^{41} \mathrm{~A}$ novel site at the patient's back has been used recently to monitor neuromuscular block at the diaphragm ${ }^{44}$ (Figure 5b) and has shown good agreement with $\mathrm{im}$ needle electromyography of the diaphragm. ${ }^{44}$ Both sites of electromyographic diaphragm recording can be used after unilateral phrenic nerve stimulation. Measurements of evoked transdiaphragmatic (Pdi) pressure have also been used to evaluate neuromuscular block at the diaphragm. ${ }^{45-49}$ Two balloons are inserted: one into the esophagus to record pleural pressure and one into the stomach to record intraabdominal pressure. The Pdi is then obtained by electronic subtraction of gastric (intra-abdominal) and esophageal (pleural) pressure.

\section{Differences between neuromuscular blockade at the diaphragm and the adductor pollicis muscle}

The technical problems mentioned above, especially the sometimes inconsistent and laborious stimulation of the phrenic nerve, have certainly limited the number of comparative studies of neuromuscular block at the diaphragm. Furthermore, earlier studies did not provide the full pharmacodynamic profile, but concentrated on the determination of the potency of several muscle relaxants at the diaphragm. ${ }^{41,45,47,50}$ Similar to the larynx, a given dose of NMBA creates less peak effect at the diaphragm than at the adductor pollicis muscle. Doses greater than the $\mathrm{ED}_{95}$ create more than $80 \%$ block at the diaphragm. Using studies where onset and clinical duration after doses higher than $\mathrm{ED}_{95}$ were simultaneously measured at the adductor 

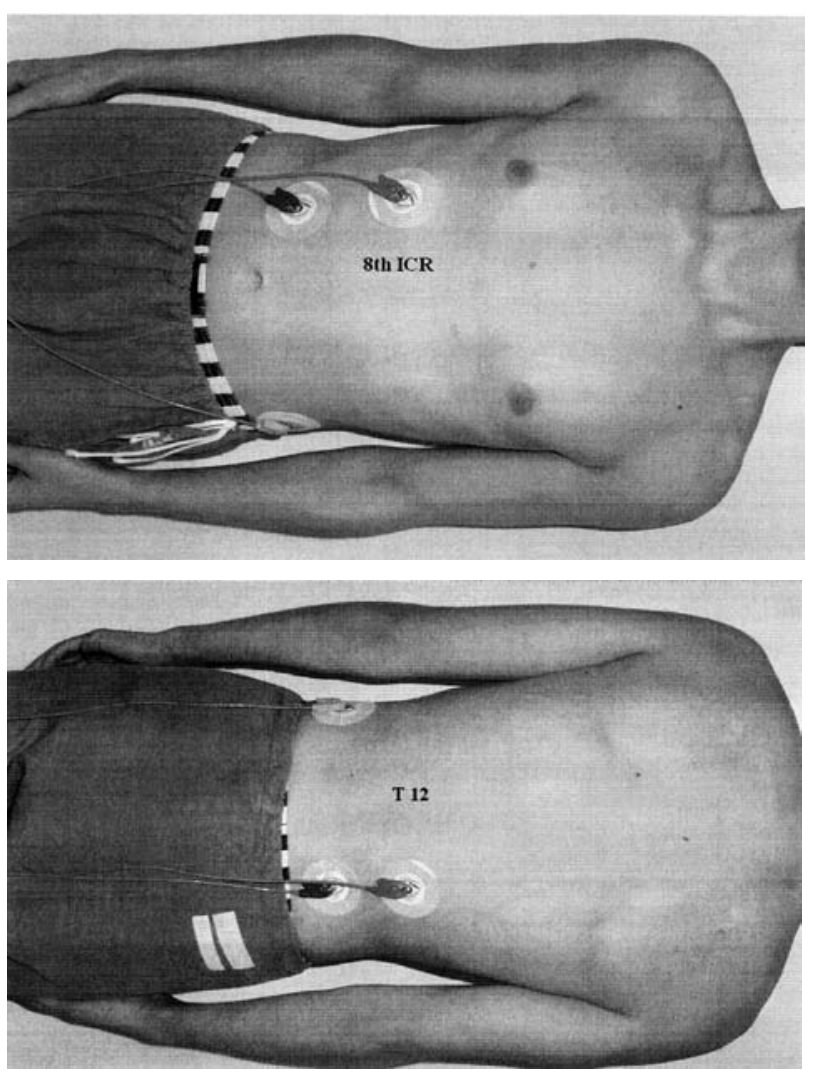

FIGURE 5 Conventional electromyographic monitoring sites for the diaphragm: (a) the seventh or eighth intercostal space, between the mid-clavicular and anterior axillary line and (b) just beside the intervertebral space of $\mathrm{T} 12-\mathrm{L} 1$ or $\mathrm{L} 1-\mathrm{L} 2$.

pollicis muscle and the diaphragm (Figure 6a, b), a lower peak effect at the diaphragm is reached after $75 \%(40-110 \%)$ of the time necessary to reach the higher peak effect at the adductor pollicis muscle. The clinical duration of the neuromuscular blockade ( $\mathrm{T}$ $25 \%)$ at the diaphragm is 60 to $80 \%(50-175 \%)$ of the clinical duration at the adductor pollicis muscle. The lower value, $60 \%$, is based on calculations where clinical duration at the diaphragm measured in one study ${ }^{13}$ is excluded: it is the only study showing a longer clinical duration at the diaphragm than at the adductor pollicis muscle (Figure 6b). Studies comparing laryngeal and diaphragmatic response after neuromuscular block indicate that the diaphragm reacts very similarly to the adductor muscles of the larynx. Onset, offset, and peak effect are quite similar for both muscle groups. In analogy to the larynx, onset and offset of neuromuscular block at the diaphragm are significantly shorter than at the adductor pollicis muscle and the peak effect is less pronounced at the diaphragm.

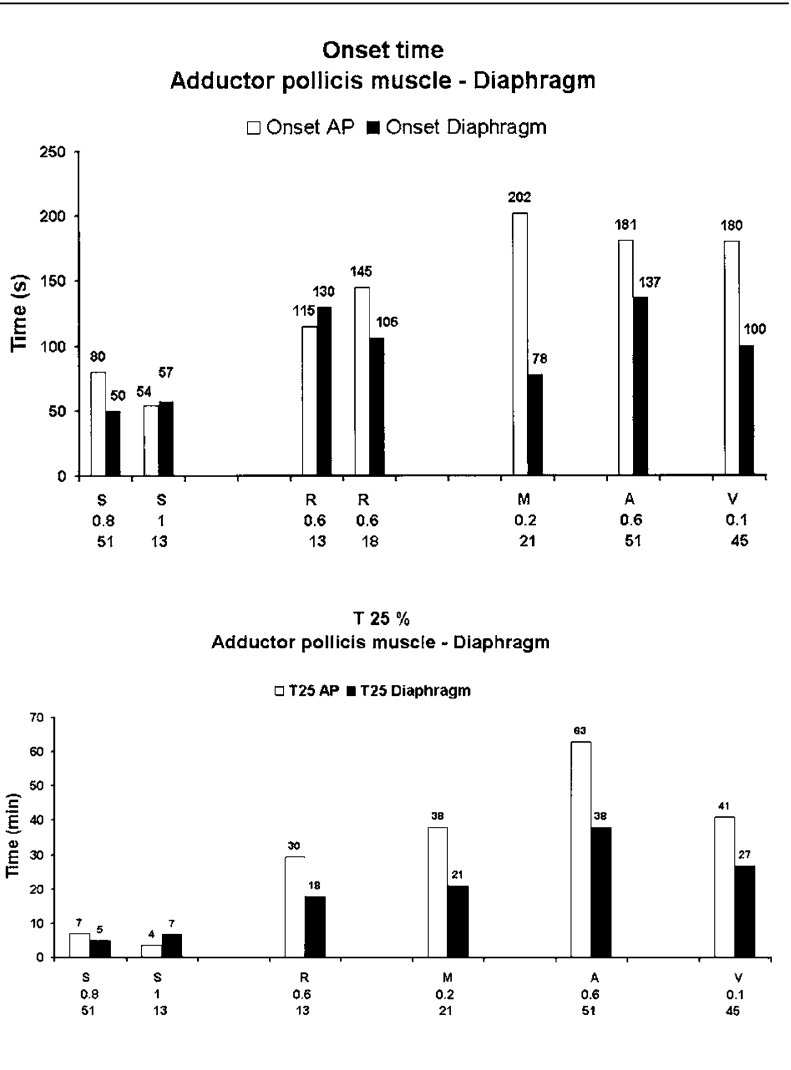

FIGURE 6 Bar graphs summarizing the results of studies that measured (a) onset and (b) clinical duration of neuromuscular blockade after injection of various neuromuscular blocking agents simultaneously at the diaphragm (black columns) and the adductor pollicis muscle (white columns). $\mathrm{A}=$ atracurium; $\mathrm{M}=$ mivacurium; $\mathrm{R}=$ rocuronium; $\mathrm{S}=$ succinylcholine; $\mathrm{V}=$ vecuronium. The second and third lines on the $\mathrm{X}$-axis indicate the doses $\left(\mathrm{mg} \cdot \mathrm{kg}^{-1}\right)$ and the reference number.

Neurophysiologic basis for the pharmacodynamic differences between the diaphragm and the adductor pollicis muscle

The dose-response of NMBAs for the diaphragm is shifted to the right compared with the adductor pollicis muscle. ${ }^{41,52,53}$ This diaphragm-sparing effect of NMBA can be explained by a higher acetylcholine receptor density, a higher acetylcholine release or lower acetylcholinesterase activity ${ }^{54,55}$ in the diaphragm. ${ }^{25}$ The small fibre size and the large endplates, relative to fibre size, of the diaphragm might contribute to the shorter duration of neuromuscular block. For cats, Ibebunjo et al. ${ }^{26}$ have found a greater number of acteylcholine receptors per muscle fibre in the diaphragm than in peripheral muscles. Increasing blood flow to muscle shortens onset time. ${ }^{56}$ The 
diaphragm receives a greater blood flow than peripheral muscles, ${ }^{27,57}$ and this might explain its shorter onset time.

The diaphragm recovers earlier than the adductor pollicis, because the greater concentration for $50 \%$ block (CP50) is higher for the diaphragm than the adductor pollicis. Recovery of neuromuscular blockade after non-depolarizing NMBAs with a short halflife, such as mivacurium, however, might be more influenced by large blood flow. ${ }^{58}$

\section{Importance of neuromuscular block at the diaphragm}

Complete neuromuscular block at the diaphragm is important for safe and easy intubation. Diaphragmatic movements during intubation, especially when combined with light anesthesia, can diminish the quality of the intubating conditions, increase the risk of regurgitation and aspiration, and increase intracranial pressure. Full recovery of neuromuscular transmission at the diaphragm is a prerequisite for extubation in order to ensure sufficient respiratory and protective diaphragmatic function immediately after extubation. ${ }^{59-63}$

Spontaneous diaphragmatic movements during surgery can also be troublesome or even endanger the safety and success of certain types of surgery (e.g., laparoscopic upper abdominal surgery, thoracic surgery, bronchoscopy) and should be avoided. Diaphragmatic movement can also endanger patients during certain procedures, such as tracheal suction, by increasing intracranial pressure. ${ }^{64}$ Increasing depth of anesthesia decreases the occurrence of spontaneous diaphragmatic movements, but it may be problematic. The fear of allergic reactions with the use of muscle relaxants ${ }^{65,66}$ the need for rapid recovery especially in day surgery, the problems of residual paralysis even with muscle relaxants of short duration, ${ }^{67}$ and economic considerations ${ }^{68}$ have led some to question the need for neuromuscular blockade. Even traditional thinking, such as the reasoning that good diaphragmatic relaxation lowers intra-abdominal pressure, and hence is necessary for abdominal surgery, has been questioned. Whereas one recent human study showed that neuromuscular blockade could improve operating conditions in abdominal surgery, ${ }^{69}$ another study in laparoscopic surgery did not show any influence of diaphragmatic relaxation on intra-abdominal pressure or inspiratory pressure..$^{70}$ Due to the complex interaction of several factors creating good operating conditions, such as depth of anesthesia, surgical exposure and skills, and the degree of muscle relaxation at the operating site, the influence of the degree of diaphragmatic relaxation on certain operating conditions is hard to judge. In practice, avoidance of spontaneous

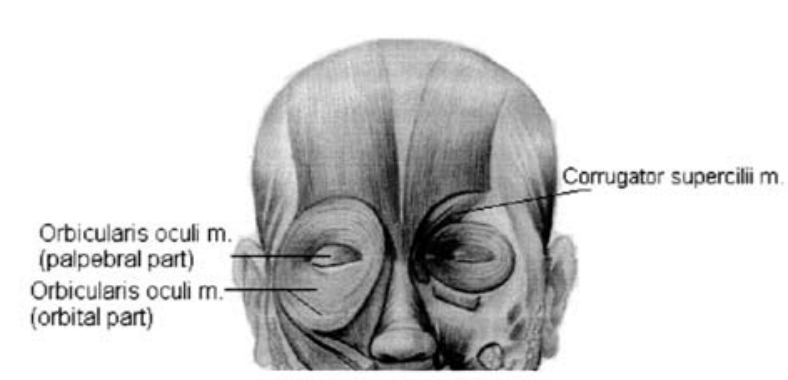

FIGURE 7 Anatomy of the corrugator supercilii muscle and the two parts of the orbicularis oculi muscle, two periorbiral muscles commonly used for neuromuscular monitoring.

diaphragmatic movements during controlled ventilation seems prudent. This can be accomplished by administration of NMBAs, by deepening the anesthetic, by giving opioid drugs, or by hyperventilation. In summary, complete block at the diaphragm provides the best intubating conditions and full recovery of neuromuscular transmission is necessary before the end of anesthesia or extubation. The role of diaphragmatic relaxation in improving surgical conditions remains unclear.

\section{The corrugator supercilii muscle}

The laryngeal adductors and the diaphragm are fastonset, rapid-recovery, resistant muscles with clinical significance in anesthesia. However, direct monitoring of their response is impractical, so a surrogate muscle must be found. Many studies have demonstrated that blockade of muscles around the eye accurately reflects the response of the laryngeal muscles and the diaphragm. This muscle, which was thought to be the orbicularis oculi, is now recognized to be the corrugator supercilii.

\section{Anatomy and physiology}

The corrugator supercilii muscle is a small muscle over the medial portion of the eyebrow and responsible for vertical frowning (Figure 7). Although in close proximity to the orbicularis oculi muscle, it is morphologically different. It contains large, polygonal fibres, with only $49 \%$ fast-twitch (type II) fibres in contrast to the orbicularis oculi, which is made up of small, rounded, predominantly (89\%) fast-twitch fibres. The corrugator supercilii also has 2.4 times as many capillaries per unit weight. ${ }^{71}$ 
Several studies have described the relationship between the response at the eyebrow and either diaphragmatic response or intubating conditions. ${ }^{42,72-75}$ The movement of the eyebrow was evaluated either visually or by electromyography. Donati et al..$^{42}$ found a striking resemblance in the time course of neuromuscular block between the eyebrow and the diaphragm. In comparison, the adductor pollicis had a slower onset, a more intense block, and later recovery. The movement of the eyebrow was attributed to the orbicularis oculi. However, accelerometric measurements performed at the anatomical location of the orbicularis oculi (over the eyelid) showed that its behaviour did not differ much from that of the adductor pollicis. ${ }^{76}$ The confusion was solved by realizing that neighbouring muscles could have very different sensitivities to neuromuscular blocking drugs. The orbicularis oculi, which moves the eyelid, is a sensitive muscle, like the adductor pollicis. The corrugator supercilii, which moves the medial aspect of the eyebrow, is more resistant. ${ }^{77}$ Responses that have been attributed to the orbicularis oculi in many investigations should, in light of current understanding of periorbital anatomy, be considered as responses from the corrugator supercilii.

\section{Stimulation of the facial nerve}

The motor branches of the facial nerve supply both the corrugator supercilii muscle and the orbicularis oculi muscle. To stimulate the facial nerve lateral to the orbit, small currents $(20-30 \mathrm{~mA})$ are recommended, in order to avoid stimulation of other facial muscles (Video 4). The use of small superficial $\mathrm{Ag}$-AgCl-electrodes is also better for avoiding stimulation of all facial muscles.

\section{Monitoring the neuromuscular blockade at the corru- gator supercilii muscle}

Recent studies have used acceleromyography $y^{21,44,77}$ and phonomyography ${ }^{78}$ to record the muscle response. Unfortunately the sensitivity required with acceleromyography is at the upper limit of the capability of most available commercial devices. A recent comparison of acceleromyography and phonomyography ${ }^{78}$ to detect neuromuscular response at the corrugator supercilii muscle has raised questions as to whether the TOF-WatchSX (Organon Technika, Boxlet, The Netherlands) is suitable to properly detect the neuromuscular response at this muscle. Electromyographic techniques have also been used, ${ }^{42,74}$ but comparisons with other methods have not been made. There is controversy as to which device is best suited for the measurement of neuromuscular block at the corrugator supercilii.
Neuromuscular blockade at the corrugator supercilii muscle in comparison to other muscles

Interest in the corrugator supercilii stems from observations that the response to facial nerve stimulation recovers faster than that of the adductor pollicis, ${ }^{42,74,79}$ similar to the diaphragm or the larynx. However, investigations have been hindered by the lack of scientifically accepted monitoring devices. At present, three studies have compared the corrugator supercilii muscle to other muscles. ${ }^{21,44,77} \mathrm{Hemmerling}$ et al. ${ }^{21}$ found the onset and offset of neuromuscular blockade at the corrugator supercilii muscle were significantly faster than at the orbicularis oculi muscle or adductor pollicis muscle, but were also significantly longer than the onset and offset of neuromuscular blockade at the larynx and diaphragm after mivacurium $0.2 \mathrm{mg} \cdot \mathrm{kg}^{-1}$.

In another study with rocuronium $0.6 \mathrm{mg} \cdot \mathrm{kg}^{-1}$, the onset and offset of neuromuscular blockade were not significantly different between the corrugator supercilii muscle and the adducting laryngeal muscles. ${ }^{77}$ Both the larynx and the corrugator supercilii were characterized by an earlier recovery than the orbicularis oculi or the adductor pollicis.

Clearly more studies are needed to further compare the neuromuscular blockade at the corrugator supercilii with other muscles. The data available so far suggest that neuromuscular blockade at the corrugator supercilii is closer to that of the larynx and the diaphragm, in comparison with the orbicularis oculi and adductor pollicis. The best monitoring site and the best monitoring method to record the response of this small muscle (in such a way that concomitant monitoring of the orbicularis oculi and production of a mixed signal is avoided) remain to be solved. Great care needs to be taken regarding the site where the facial nerve is stimulated in order to produce a maximal response (Video 5 ).

A first attempt has been made with a recent study ${ }^{78}$ that investigated the best recording site and evaluated the usefulness of phonomyography to monitor the neuromuscular block. A contracting muscle emits low-frequency sounds; phonomyography is a technique designed to pick up these acoustic signals. The best recording site was just lateral to the actual muscle, in the middle of the area just above the eyebrow. The study also found a significant difference between acceleromyography and phonomyography in the ability to record neuromuscular block at this muscle. The findings suggested that acceleromyography using the TOF-Watch may be inadequate to monitor this muscle whereas phonomyography was a reliable and sensitive monitor. Comparative studies with laryngeal and diaphragmatic responses are needed to evaluate the usefulness of phonomyography. 
What is the place of the corrugator supercilii muscle in neuromuscular monitoring?

Of all the peripheral muscles used for monitoring over the years, the corrugator supercilii muscle may be the one that most closely resembles the laryngeal muscles in terms of response to NMBAs. It is accessible during most types of surgery. Future studies comparing its response with laryngeal and diaphragmatic responses, and studies to correlate corrugator supercilii relaxation with surgical conditions are needed.

As noted previously, questions have risen about the sensitivity and reliability of acceleromyography at the corrugator supercilii muscle. ${ }^{78}$ Phonomyography seems a promising method because it is highly sensitive, reliable, and reproducible; however, no commercial devices are available. At present, visual inspection of the response to facial nerve stimulation is the only method available.

\section{Which muscle should be used to determine the optimal conditions for intubation?}

Some studies have focused on the visual estimation of complete neuromuscular block around the eye to determine optimal time for intubation. ${ }^{72,73,80}$ Presumably, if no neuromuscular activity is detected, the most resistant muscle in the area, the corrugator supercilii, must be blocked, even if the authors of these studies have frequently misidentified the muscle as the orbicularis oculi. For intubating doses of vecuronium, mivacurium, atracurium, rocuronium, and succinylcholine, visual estimation of onset time around the eye has been shown to be sufficient to determine the optimal and earliest time for intubation. Good-to-excellent intubating conditions were observed in more than $90 \%$ of the patients. Similar results have been found in children, where visual estimation of onset of neuromuscular block around the eye predicted good-to-excellent intubating conditions in all children earlier than the adductor pollicis muscle. ${ }^{73}$

In contrast to pharmacodynamic data, which are difficult to compare between studies, even if the same dose and muscle relaxant is used, clinical criteria (ease of ventilation, jaw and upper airway tone) used in one study $^{81}$ after rocuronium $0.6 \mathrm{mg} \cdot \mathrm{kg}^{-1}$ produced good to excellent intubating conditions after a similar onset time when compared to another study ${ }^{77}$ that used onset at muscles around the eye (mean of $89 \sec v s 99$ sec respectively).

The role of the visual estimation of a complete block around the eye as a predictor of good intubating conditions is controversial. Another study ${ }^{82}$ has found poor intubating conditions in $14 \%$ of 30 patients after vecuronium $0.1 \mathrm{mg} \cdot \mathrm{kg}^{-1}$, which contra- dicts the study by Le Corre et al. ${ }^{72}$ Due to the fact that all these studies used visual estimation of onset of neuromuscular blockade, a subjective element renders the comparisons between these studies difficult. It may be useful to use the aforementioned objective methods and judge the correlation between onset time at complete block at the orbicularis oculi and good intubating conditions. The problem with the comparisons between these studies is that the degree of neuromuscular blockade, at which intubation was attempted, cannot be deduced objectively.

\section{A look at the future}

\section{The role of determination of laryngeal neuromuscular} blockade

So far, most monitoring methods have been used for research purposes. We know that onset and offset at the adducting laryngeal muscles occur far earlier than at the adductor pollicis muscle and peak effect is less pronounced. The faster onset can be explained by the more rapid blood flow and therefore earlier arrival of muscle relaxant at the receptor site. Differences in fibre size and composition between the laryngeal muscles and peripheral muscles explain the lesser degree of neuromuscular block and the faster laryngeal recovery at equipotent doses.

For clinical purposes, a direct method of monitoring laryngeal neuromuscular blockade would be helpful in determining onset of block and complete recovery. At present, percutaneous stimulation of the recurrent laryngeal nerve using superficial electrodes is possible and easy. However, there is no non-invasive monitoring system available to monitor the laryngeal response before insertion of either the endotracheal tube or the monitoring devices. Other than for research purposes, monitoring of laryngeal neuromuscular transmission is only used for intraoperative monitoring of the recurrent laryngeal nerve in thyroid surgery. ${ }^{83}$

\section{The role of determination of diaphragmatic neuromus- cular blockade}

Diaphragmatic electromyographic monitoring is a wellestablished method in research and has been used to measure the time course of neuromuscular blockade after various NMBAs. There are very few studies in which objective methods of diaphragmatic monitoring were used to investigate the clinical importance of diaphragmatic relaxation for optimal conditions in laparoscopic or open abdominal surgery. The main problem with conventional monitoring methods is the location of the site within the sterile surgical field. The recent description of a novel site of monitoring situated at the back of the patient ${ }^{84}$ may lead to more research in this area. 


\section{The role of the corrugator supercilii muscle}

The recent anatomic differentiation between the corrugator supercilii muscle and the orbicularis oculi muscle has led to a better understanding of which facial muscle should be monitored. In practice, the name of the muscle is irrelevant, and it may be assumed that the most resistant muscle (the corrugator supercilii) will be the one which is least likely to be blocked during onset. Visual estimation of onset using stimulation of the facial nerve $\mathrm{e}^{72}$ to judge optimal timing for intubation most probably entails inspection of the corrugator supercilii muscle, and not the orbicularis oculi muscle. When no movement at the eyebrow is observed following stimulation of the facial nerve, intubating conditions are as good as when one proceeds after a fixed time (such as three minutes) or if one waits until the adductor pollicis is completely blocked. The advantage of using facial nerve stimulation is that the time interval before attempted intubation is shortened. The hypothesis that continuous intraoperative monitoring of the corrugator supercilii muscle might not only reflect the neuromuscular block at the adducting laryngeal muscle but also at the diaphragm or the abdominal muscles, needs further study. It might be that monitoring of this muscle gives us a better estimate of diaphragmatic or abdominal relaxation.

\section{A short reflection on today's monitoring methods for the clinician}

Mechanomyography has long been considered to be the gold standard of neuromuscular monitoring. It is the only method to directly measure the force created by the contraction of a muscle. It has so far mainly been used as a research tool and mostly at the adductor pollicis muscle. In practice, mechanomyographic devices need time to set up, because of the necessity to fix the arm in some kind of cast and apply a certain preload. It can only be applied to the adductor pollicis muscle. The introduction of the Datex Ohmeda Mechanosensor, integrated in the latest Datex Ohmeda anesthesia machine, tries to solve the problem of elaborate set-up by designing a device that is attached to the thumb and index finger and records movement after contraction of the muscle. The device does not measure isometric force, because some movement is allowed following contraction. There is no published information of its principle of operation. Recently, a comparison between the Mechanosensor and a force transducer has been published. ${ }^{85}$ Unexplained differences in the time to early recovery, when the anesthesiologist may decide to give another dose of relaxant or to administer a reversal drug, were found. However, both monitors agreed well in the estimates of late recovery parameters. Further studies are warranted.
Acceleromyography is the only method available to the clinician than can offer objective data on neuromuscular block at the adductor pollicis muscle, orbicularis oculi muscle, and corrugator supercilii muscle. This method has been in use for more than ten years, and is useful especially during onset of neuromuscular block and recovery. There are many studies that have demonstrated good correlation with mechanomyographically measured recovery: The TOF-Guard ${ }^{\circledR}$ is no longer on the market, but is replaced by the TOF-Watch ${ }^{\circledR}$ and TOF-Watch SX®. It is a useful device and one of the standard monitoring methods in clinical routine.

Phonomyography (or acoustic myography) is in development as an alternative method and might have advantages at the eye muscles and can be used at any muscle, including larynx and diaphragm.

\section{Recommendations}

1) Determination of the Shortest interval FOR INTUBATION WITH NEUROMUSCULAR BLOCKADE If speed of intubation is of importance, such as during rapid sequence induction, the facial nerve may be stimulated just lateral the eyebrow with a single twitch every ten seconds with a current intensity of 20 to 30 $\mathrm{mA}$ (Video 5), and the response of the corrugator supercilii muscle (medial part of the eyebrow) may be observed. When there is no response, laryngoscopy and intubation can be attempted.

If acceleromyography is available, objective determination of onset time at the corrugator supercilii muscle with the same stimulation mode can be observed and intubation performed at maximum block. The sensitivity of the accelerometer must be set at the highest level.

\section{2) RECOVERY OF NEUROMUSCULAR TRANSMISSION AT THE END OF SURGERY}

Complete recovery of neuromuscular function of all muscles is necessary for safe extubation. Twitch height returns relatively early at the corrugator supercilii, so this muscle is not appropriate to judge recovery. Neuromuscular function is slow to return at the upper airway muscles and at the adductor pollicis muscle. The latter should be monitored. TOF ratios of more than 0.8 or 0.9 are necessary ${ }^{86}$ Since this is difficult to assess visually or manually, objective neuromuscular monitoring using acceleromyography is the best and most practical method available to the clinician at present. It is very important to remember that even a TOF ratio of $l$ at the corrugator supercilii muscle may be accompanied by a fade at more peripheral muscles such as the adductor pollicis muscle. 


\section{3 ) Control of neuromuscular blockade DURING SURGERY}

With an adequate depth of anesthesia, many surgeries do not require complete neuromuscular blockade. However, there are still enough types of surgery that demand a high and continuous degree of neuromuscular blockade. Neuromuscular research during the last 15 years has led to a much better understanding of differential neuromuscular blockade: the idea of a surgery-specific neuromuscular blockade can be deduced. For peripheral surgery, such as orthopedic surgery, neuromuscular monitoring of the adductor pollicis muscle is the best monitor of muscle relaxation at the surgical site. Objective monitoring can be used to titrate neuromuscular blockade to the desired degree, though for peripheral surgery a high degree of neuromuscular block at the adductor pollicis muscle may be unnecessary.

More central types of surgery, such as closed or open abdominal surgery, thoracic surgery, and laryngeal surgery require neuromuscular blockade of the diaphragm or abdominal muscles. Since, at present, neuromuscular monitoring at the diaphragm is clinically impossible and since monitoring of the adductor pollicis muscle again would underestimate the diaphragmatic neuromuscular blockade, monitoring of the corrugator supercilii muscle would be advantageous.

\section{Conclusion}

Research during the last decade and a half has lead to an increased understanding of neuromuscular transmission and blockade at different muscles. Neuromuscular blockade at the larynx and the diaphragm is less intense than at the adductor pollicis muscle, while onset and offset of neuromuscular blockade are more rapid. The corrugator supercilii muscle has recently been identified as a muscle that is easy to monitor and reflects better the time course of neuromuscular blockade of the larynx, and possibly the diaphragm. It is better suited to monitor the onset of neuromuscular blockade for intubation, and should give a better reflection of neuromuscular blockade of the diaphragm. Monitoring this muscle allows better titration of neuromuscular blockade during surgery where a certain degree of diaphragmatic block is necessary or desired. Recovery of neuromuscular function of most muscles is best reflected by the adductor pollicis muscle.

Whereas the establishment of the corrugator supercilii muscle as an additional peripheral muscle for clinical neuromuscular monitoring has led to a more refined and detailed titration of neuromuscular block, it has also highlighted the lack of a reliable, objective, and easy-to-use monitoring device for the clinician. The use of acceleromyography at the corrugator supercilii muscle is limited by artifacts, which do not occur during monitoring of the adductor pollicis muscle. The fact that its methodology relies on measuring acceleration of a muscle limits its use at muscles where muscle contraction does not create sufficient movement and acceleration.

If future research shows better agreement of phonomyography with established method of monitoring, then this method may supersede acceleromyography, because it can be easily used at all muscles. Routine monitoring of neuromuscular blockade at the larynx or the diaphragm is limited by the absence of noninvasive methods to monitor the laryngeal muscles and the difficulty of percutaneous stimulation of the phrenic nerve. Future research will show whether these problems can be solved or not.

\section{References}

1 Platzer W. Pernkopf Anatomy: Atlas of Topographic and Applied Human Anatomy, 3rd ed., Baltimore: Urban \& Schwarzenberg; 1989: 383.

2 Rossi G, Cortesina G. Multi-motor end-plate muscle fibres in the human vocalis muscle. Nature 1965; 206: 629-30.

3 Morales J, Rama J, Gayoso M. Some aspects of the nerve endings and synapses in the vocalis muscle. J Laryngol Otol 1980; 94: 1047-63.

4 Sahgal V, Hast MH. Histochemistry of primate laryngeal muscles. Acta Otolaryngol 1974; 78: 277-81.

5 Andel H, Klune G, Andel D, et al. Propofol without muscle relaxants for conventional or fiberoptic nasotracheal intubation: a dose-finding study. Anesth Analg 2000; 91: 458-61.

6 Hovorka J, Honkavaara P, Korttila K. Tracheal intubation after induction of anaesthesia with thiopentone or propofol without muscle relaxants. Acta Anaesthesiol Scand 1991; 35: 326-8.

7 Schlaich N, Mertzlufft F, Soltesz S, Fuchs-Buder T. Remifentanil and propofol without muscle relaxants or with different doses of rocuronium for tracheal intubation in outpatient anaesthesia. Acta Anaesthesiol Scand 2000; 44: 720-6.

8 Fuchs-Buder T. Intubation without muscle relaxants: options and limitations (German). Anasthesiol Intensivmed Notfallmed Schmerzther 2000; 35: 106-8.

9 Haeseler G, Stormer M, Mohammadi B, et al. The anesthetic propofol modulates gating in paramyotonia congenita mutant muscle sodium channels. Muscle Nerve 2001; 24: 736-43.

10 Hemmerling TM, Schurr C, Dern S, Schmidt J, Braun 
$G G$, Klein P. Intraoperative electromyographic recurrent laryngeal nerve identification as a routine measure (German). Chirurg 2000; 71: 545-50.

11 Donati F, Plaud B, Meistelman C. A method to measure elicited contraction of laryngeal adductor muscles during anesthesia. Anesthesiology 1991; 74: 827-32.

12 Girling KJ, Bedforth NM, Spendlove JL, Mahajan RP. Assessing neuromuscular block at the larynx: the effect of change in resting cuff pressure and a comparison with video imaging in anesthetized humans. Anesth Analg 1999; 88: 426-31.

13 Dhonneur G, Kirov K, Slavov V, Duvaldestin P. Effects of an intubating dose of succinylcholine and rocuronium on the larynx and diaphragm: an electromyographic study in humans. Anesthesiology 1999; 90: 951-5.

14 Hemmerling TM, Schurr C, Walter S, Dern S, Schmidt $J$, Braun GG. A new method of monitoring the effect of muscle relaxants on laryngeal muscles using surface laryngeal electromyography. Anesth Analg 2000; 90: 494-7.

15 Hemmerling TM, Schmidt J, Wolf T, Wolf SR, Jacobi $K E$. Surface $v s$ intramuscular laryngeal electromyography. Can J Anesth 2000; 47: 860-5.

16 Meistelman C, Plaud B, Donati F. Neuromuscular effects of succinylcholine on the vocal cords and adductor pollicis muscles. Anesth Analg 1991; 73: 278-82.

17 Wright PM, Caldwell JE, Miller RD. Onset and duration of rocuronium and succinylcholine at the adductor pollicis and laryngeal adductor muscles in anesthetized humans. Anesthesiology 1994; 81: 1110-5.

18 Hemmerling TM, Schmidt J, Wolf T, Klein P, Jacobi K. Comparison of succinylcholine with two doses of rocuronium using a new method of monitoring neuromuscular block at the laryngeal muscles by surface laryngeal electromyography. Br J Anaesth 2000; 85: 251-5.

19 Meistelman C, Plaud B, Donati F. Rocuronium (ORG 9426) neuromuscular blockade at the adductor muscles of the larynx and adductor pollicis in humans. Can J Anaesth 1992; 39: 665-9.

20 Plaud B, Debaene B, Lequeau F, Meistelman C, Donati $F$. Mivacurium neuromuscular block at the adductor muscles of the larynx and adductor pollicis in humans. Anesthesiology 1996; 85: 77-81.

21 Hemmerling TM, Schmidt J, Hanusa C, Wolf T, Schmitt $H$. Simultaneous determination of neuromuscular block at the larynx, diaphragm, adductor pollicis, orbicularis oculi and corrugator supercilii muscles. Br J Anaesth 2000; 85: 856-60.

22 Donati F, Meistelman C, Plaud B. Vecuronium neuromuscular blockade at the adductor muscles of the larynx and adductor pollicis. Anesthesiology 1991; 74: 833-7.
23 Kim KS, Chung CW, Shin WJ. Cisatracurium neuromuscular block at the adductor pollicis and the laryngeal adductor muscles in humans. Br J Anaesth 1999; 83: 483-4.

24 Debaene B, Lieutaud T, Billard V, Meistelman C. ORG 9487 neuromuscular block at the adductor pollicis and the laryngeal adductor muscles in humans. Anesthesiology 1997; 86: 1300-5.

25 Sterz R, Pagala M, Peper K. Postjunctional characteristics of the endplates in mammalian fast and slow muscles. Pflugers Arch 1983; 398: 48-54.

26 Ibebunjo C, Srikant CB, Donati F. Morphological correlates of the differential responses of muscles to vecuronium. Br J Anaesth 1999; 83: 284-91.

27 Donati F. Onset of action of relaxants. Can J Anaesth 1988; 35: S52-8.

28 Michalek-Sauberer A, Gilly H, Steinbereithner K, Vizi $E S$. Effects of vecuronium and rocuronium in antagonistic laryngeal muscles and the anterior tibial muscle in the cat. Acta Anaesthesiol Scand 2000; 44: 503-10.

29 Iwasaki $H$, Igarashi $M$, Namiki A, Omote $K$. Differential neuromuscular effects of vecuronium on the adductor and abductor laryngeal muscles and tibialis anterior muscle in dogs. Br J Anaesth 1994; 72: 321-3.

30 Iwasaki $H$, Igarashi $M$, Omote $K$, Namiki $A$. Vecuronium neuromuscular blockade at the cricothyroid and posterior cricoarytenoid muscles of the larynx and at the adductor pollicis muscle in humans. J Clin Anesth 1994; 6: 14-7.

31 Bellemare F, Bigland-Ritchie B. Assessment of human diaphragm strength and activation using phrenic nerve stimulation. Respir Physiol 1984; 58: 263-77.

32 Similowski T, Fleury B, Launois S, Cathala HP, Bouche P, Derenne JP. Cervical magnetic stimulation: a new painless method for bilateral phrenic nerve stimulation in conscious humans. J Appl Physiol 1989; 67: 1311-8.

33 Similowski T, Fleury B, Launois S, Cathala HP, Bouche $P$, Derenne JP. Cervical magnetic stimulation. A new method of bilateral phrenic nerve stimulation for use in clinical practice (French). Rev Mal Respir 1988; 5: 609-14.

34 Mouchawar G, Bourland JD, Voorhees WD, Geddes LA. Stimulation of inspiratory motor nerves with a pulsed magnetic field (Letter). Med Biol Eng Comput 1990; 28: 613 .

35 Mouchawar GA, Bourland JD, Geddes LA, Nyenhuis $J A$. Magnetic electrophrenic nerve stimulation to produce inspiration. Ann Biomed Eng 1991; 19: 219-21.

36 Geddes LA. History of magnetic stimulation of the nervous system. J Clin Neurophysiol 1991; 8: 3-9.

37 Wragg S, Aquilina R, Moran J, et al. Comparison of cervical magnetic stimulation and bilateral percuta- 
neous electrical stimulation of the phrenic nerves in normal subjects. Eur Respir J 1994; 7: 1788-92.

38 Mador MJ, Rodis A, Magalang UJ, Ameen K. Comparison of cervical magnetic and transcutaneous phrenic nerve stimulation before and after threshold loading. Am J Respir Crit Care Med 1996; 154: 448-53.

39 Similowski T, Mehiri S, Duguet A, Attali V, Straus C, Derenne JP. Comparison of magnetic and electrical phrenic nerve stimulation in assessment of phrenic nerve conduction time. J Appl Physiol 1997; 82: 1190-9.

40 Verin E, Straus C, Demoule A, Mialon P, Derenne JP, Similowski $T$. Validation of improved recording site to measure phrenic conduction from surface electrodes in humans. J Appl Physiol 2002; 92: 967-74.

41 Donati F, Antzaka C, Bevan DR. Potency of pancuronium at the diaphragm and the adductor pollicis muscle in humans. Anesthesiology 1986; 65: 1-5.

42 Donati F, Meistelman C, Plaud B. Vecuronium neuromuscular blockade at the diaphragm, the orbicularis oculi, and adductor pollicis muscles. Anesthesiology 1990; 73: 870-5.

43 Dhonneur G, Rebaine C, Slavov V, Ruggier R, De C V, Duvaldestin $P$. Neostigmine reversal of vecuronium neuromuscular block and the influence of renal failure. Anesth Analg 1996; 82: 134-8.

44 Hemmerling TM, Schmidt J, Wolf T, Hanusa C, Siebzehnruebl E, Schmitt H. Intramuscular versus surface electromyography of the diaphragm for determining neuromuscular blockade. Anesth Analg 2001; 92: 106-11.

45 Chauvin M, Lebrault C, Duvaldestin P. The neuromuscular blocking effect of vecuronium on the human diaphragm. Anesth Analg 1987; 66: 117-22.

46 Derrington MC, Hindocha N. Measurement of evoked diaphragm twitch strength during anaesthesia.

Adaptation and evaluation of an existing technique. $\mathrm{Br}$ J Anaesth 1988; 61: 270-8.

47 Derrington $M C$, Hindocha N. Comparison of neuromuscular blockade in the diaphragm and the hand. Br J Anaesth 1988; 61: 279-85.

48 Lebrault C, Chauvin M, Guirimand F, Duvaldestin P. Relative potency of vecuronium on the diaphragm and the adductor pollicis. Br J Anaesth 1989; 63: 389-92.

49 Cantineau JP, Porte F, d'Honneur G, Duvaldestin P. Neuromuscular effects of rocuronium on the diaphragm and adductor pollicis muscles in anesthetized patients. Anesthesiology 1994; 81: 585-90.

50 Wymore ML, Eisele JH. Differential effects of d-tubocurarine on inspiratory muscles and two peripheral muscle groups in anesthetized man. Anesthesiology 1978; 48: 360-2.
51 Pansard JL, Chauvin M, Lebrault C, Gauneau P, Duvaldestin P. Effect of an intubating dose of succinylcholine and atracurium on the diaphragm and the adductor pollicis muscle in humans. Anesthesiology 1987; 67: 326-30.

52 Laycock JR, Donati F, Smith CE, Bevan DR. Potency of atracurium and vecuronium at the diaphragm and the adductor pollicis muscle. Br J Anaesth 1988; 61: 286-91.

53 Lebrault C, Chauvin M, Brusset A, Duvaldestin P. Comparison of the antagonistic effects of neostigmine and edrophonium on neuromuscular block induced by vecuronium in the diaphragm and thumb adductor (French). Ann Fr Anesth Reanim 1989; 8(Suppl): Rl28.

54 Wand BE, Wand DR. The relation between the response to "train-of-four" stimulation and receptor occlusion during competitive neuromuscular block. Anesthesiology 1972; 37: 413-6.

$55 \mathrm{Lu}$ TC. Affinity of curare-like compounds and their potency in blocking neuromuscular transmission. J Pharmacol Exp Ther 1970; 174: 560-6.

56 Goat VA, Yeung ML, Blakeney C, Feldman SA. The effect of blood flow upon the activity of gallamine triethiodide. Br J Anaesth 1976; 48: 69-73.

57 Robertson CH Jr, Pagel MA, Johnson RL Jr. The distribution of blood flow, oxygen consumption, and work output among the respiratory muscles during unobstructed hyperventilation. J Clin Invest 1977; 59: 43-50.

58 Abdulatif $M$, el Sanabary $M$. Blood flow and mivacurium-induced neuromuscular block at the orbicularis oculi and adductor pollicis muscles. Br J Anaesth 1997; 79: 24-8.

59 Isono S, Ide T, Kochi T, Mizuguchi T, Nishino T. Effects of partial paralysis on the swallowing reflex in conscious humans. Anesthesiology 1991; 75: 980-4.

60 Pavlin EG, Holle RH, Schoene RB. Recovery of airway protection compared with ventilation in humans after paralysis with curare. Anesthesiology 1989; 70: 381-5.

61 Beemer GH, Rozental P. Postoperative neuromuscular function. Anaesth Intensive Care 1986; 14: 41-5.

62 Bevan DR, Smith CE, Donati F. Postoperative neuromuscular blockade: a comparison between atracurium, vecuronium, and pancuronium. Anesthesiology 1988; 69: 272-6.

63 Katz RL. Neuromuscular effects of d-tubocurarine, edrophonium and neostigmine in man. Anesthesiology 1967; 28: 327-36.

64 Werba A, Klezl M, Schramm W, et al. The level of neuromuscular block needed to suppress diaphragmatic movement during tracheal suction in patients with raised intracranial pressure: a study with vecuronium and atracurium. Anaesthesia 1993; 48: 301-3. 
65 Laake JH, Rottingen JA. Rocuronium and anaphylaxis-a statistical challenge. Acta Anaesthesiol Scand 2001; 45: 1196-203.

66 Laxenaire MC. Epidemiology of anesthetic anaphylactoid reactions. Fourth multicenter survey (July 1994December 1996) (French). Ann Fr Anesth Reanim 1999; 18: 796-809.

67 Bevan DR, Kabwaji R, Ansermino JM, et al. Residual block after mivacurium with or without edrophonium reversal in adults and children. Anesthesiology 1996; 84: 362-7.

68 Eger EI, White PF, Bogetz MS. Clinical and economic factors important to anaesthetic choice for day-case surgery. Pharmacoeconomics 2000; 17: 245-62.

69 King M, Sujirattanawimol N, Danielson DR, Hall BA, Schroeder DR, Warner DO. Requirements for muscle relaxants during radical retropubic prostatectomy. Anesthesiology 2000; 93: 1392-7.

70 Chassard D, Berrada K, Tournadre J, Bouletreau P. The effects of neuromuscular block on peak airway pressure and abdominal elastance during pneumoperitoneum. Anesth Analg 1996; 82: 525-7.

71 Goodmurphy CW, Ovalle WK. Morphological study of two human facial muscles: orbicularis oculi and corrugator supercilii. Clin Anat 1999; 12: 1-11.

72 Le Corre F, Plaud B, Benhamon E, Debaene B. Visual estimation of onset time at the orbicularis oculi after five muscle relaxants: application to clinical monitoring of tracheal intubation. Anesth Analg 1999; 89: 1305-10.

73 Pland B, Laffon M, Ecoffey C, Meistelman C. Monitoring orbicularis oculi predicts good intubating conditions after vecuronium in children. Can J Anaesth 1997; 44: 712-6.

74 Sayson SC, Mongan PD. Onset of action of mivacurium chloride. A comparison of neuromuscular blockade monitoring at the adductor pollicis and the orbicularis oculi. Anesthesiology 1994; 81: 35-42.

75 Ungureanu D, Meistelman C, Frossard J, Donati F. The orbicularis oculi and the adductor pollicis muscles as monitors of atracurium block of laryngeal muscles. Anesth Analg 1993; 77: 775-9.

76 Rimaniol JM, Dhonneur G, Sperry L, Duvaldestin P. A comparison of the neuromuscular blocking effects of atracurium, mivacurium, and vecuronium on the adductor pollicis and the orbicularis oculi muscle in humans. Anesth Analg 1996; 83: 808-13.

77 Plaud B, Debaene B, Donati F. The corrugator supercilii, not the orbicularis oculi, reflects rocuronium neuromuscular blockade at the laryngeal adductor muscles. Anesthesiology 2001; 95: 96-101.

78 Hemmerling TM, Donati F, Beaulieu P, Babin D. Phonomyography of the corrugator supercilii muscle: signal characteristics, best recording site and comparison with acceleromyography. Br J Anaesth 2002; 88: 389-93.

79 Caffrey RR, Warren ML, Becker KE Jr. Neuromuscular blockade monitoring comparing the orbicularis oculi and adductor pollicis muscles. Anesthesiology 1986; 65: 95-7.

80 Debaene B, Beaussier M, Meistelman C, Donati F, Lienhart $A$. Monitoring the onset of neuromuscular block at the orbicularis oculi can predict good intubating conditions during atracurium-induced neuromuscular block. Anesth Analg 1995; 80: 360-3.

81 Smith I, Saad RS. Comparison of intubating conditions after rocuronium or vecuronium when the timing of intubation is judged by clinical criteria. Br J Anaesth 1998; 80: 235-7.

82 Koscielniak-Nielsen ZJ, Horn A, Sztuk F, Eriksen K, Skovgaard LT, Viby-Mogensen J. Timing of tracheal intubation: monitoring the orbicularis oculi, the adductor pollicis or use a stopwatch? Eur J Anaesthesiol 1996; 13: 130-5.

83 Hemmerling TM, Schmidt J, Bosert C, Jacobi KE, Klein $P$. Intraoperative monitoring of the recurrent laryngeal nerve in 151 consecutive patients undergoing thyroid surgery. Anesth Analg 2001; 93: 396-9.

84 Hemmerling TM, Schmidt J, Hanusa C, Wolf T, Jacobi $K E$. The lumbar paravertebral region provides a novel site to assess neuromuscular block at the diaphragm. Can J Anesth 2001; 48: 356-60.

85 Dahaba $A A$, von Klobucar F, Rebak PH, List WF. The neuromuscular transmission module versus the relaxometer mechanomyograph for neuromuscular block monitoring. Anesth Analg 2002; 94: 591-6.

86 Berg H, Roed J, Viby-Mogensen J, et al. Residual neuromuscular block is a risk factor for postoperative pulmonary complications. A prospective, randomised, and blinded study of postoperative pulmonary complications after atracurium, vecuronium and pancuronium. Acta Anaesthesiol Scand 1997; 41: 1095-103. 